\title{
COGNITIVE EMOTION REGULATION IN CHILDREN AS RELATED TO THEIR PARENTING STYLE, FAMILY TYPE AND GENDER
}

\author{
A.K.M. REZAUL KARIM ${ }^{1}$, TANIA SHARAFAT AND ABU YUSUF MAHMUD ${ }^{2}$ \\ Department of Psychology, University of Dhaka, Dhaka1000 \\ ${ }^{2}$ Department of Psychology, Dhaka College, Dhaka1205
}

\begin{abstract}
This study aimed to investigate whether cognitive emotion regulation in children varies with parenting style, family type and gender. Toward this end, cognitive emotion regulation and perceived parenting style of 206 school children were measured. Standard regression analyses of data revealed that the models were significant and explained $17.3 \%$ of the variance in adaptive emotion regulation (Adjusted $R^{2}=0.173 ; F=9.579$, $p<.001$ ), and $7.1 \%$ of the variance in less adaptive emotion regulation (Adjusted $\left.R^{2}=.071, F=4.135, p=.001\right)$. Results showed that children's cognitive emotion regulation is functionally associated with parenting style, but not with family type and their gender. Amongst the three types of parenting, authoritative parenting was the strongest predictor of overall adaptive emotion regulation while authoritarian parenting was the strongest predictor of overall less adaptive emotion regulation. Permissive parenting has impact on neither adaptive nor less adaptive emotion regulation. The findings have implications for parents, caregivers, child psychologists and other professionals working with children/ adolescents.
\end{abstract}

Key words: Cognitive emotion regulation, Adaptive, Less adaptive, Parenting style, Family type

\section{Introduction}

In everyday life we often experience strong emotions that need to be managed in order to function well in the family, office or workplace, and community or society etc. Managing or regulating emotions mean understanding and filtering emotional experience, using healthy strategies to control uncomfortable emotions and engaging in appropriate behavior (e.g. attending classes, going to work, engaging in friendships or social relationships) when distressed. Emotion regulation has both cognitive and behavioral aspects. We are interested here in the cognitive aspect of emotion regulation of adolescents. Cognitive emotion regulation is defined as the conscious, cognitive way of managing the intake of emotionally arousing information (Thompson 1994). The cognitive strategies that people generally use to regulate their emotions in different settings can be divided into two broad categories: adaptive strategies and less adaptive strategies.

Researchers have shown that the neurological changes improve the regulation of emotion over the course of adolescence. As adolescents grow they also learn how to regulate emotions which has both positive and negative impacts on their relationships with

\footnotetext{
${ }^{1}$ Corresponding author: Email: karim.akmr.monscho06@gmail.com
} 
family, neighbors and friends. However, we still do not know about the role of parents or family in its development. Thus we are interested to see what kind of strategies children use (Adaptive or Less Adaptive?) in what kind of family and parenting situations to regulate their emotions. The child's interactions with the family members in general and with the parents in particular can play a crucial role in its cognitive and socio-emotional development (McLanahan and Bumpass 1988). This role can be much more important in a collectivistic society such as in Bangladesh where there are mainly two types of family: nuclear family and extended family.

Although children at adolescence give more importance to their peer group than parents, but parents and families have strong influence over them. Berndt (1979), and Young and Ferguson (1979), for example, found that although both sexes are highly peer-oriented, males and females at different times in adolescence are influenced by their parents. Parenting styles have been described as the collection of parents' behaviors which create an atmosphere of parent-child interactions across situations (Mize and Pettit 1997). Authoritative parents offer a balance between high nurturance and high control, they do not reward dependency (Baumrind and Black 1967), but instead set a standard of responsibility and self-control. Here, expectations are clear, rules are firm and rational, and discipline is administered in a consistent manner (Baumrind 1978). Thus authoritarian parenting is characterized by high control with low levels of parental warmth, involvement, support, or emotional commitment (Baumrind and Black 1967). Permissive/indulgent parents allow their children to do whatever they wish and they are characterized by high levels of warmth and low levels of control over children. In this style of parenting children are often left to regulate their own activities, behavior, and emotions at a young age.

The period of adolescence forms an important stage in the development of cognitive coping skills as this is the period in which the more advanced cognitive abilities are being mastered. Studies have shown that children's emotion regulation can be dependent on the style of parenting. Children of authoritarian parents on the other hand have been shown to be dissatisfied, apprehensive, fearful, socially inhibited, aggressive, and experience difficulty in regulating emotions (Baumrind 1967, Baumrind and Black 1967, Hart et al. 1998, Hart et al. 2003, Nix et al. 1999). Permissive parenting has been linked to bossy, dependant, impulsive behavior in children, with low levels of self-control and achievement; these children do not learn persistence and emotional control (Baumrind 1967). One limitation of these studies is that they are biased to the scenario of individualistic societies. A second limitation is that they mostly focused on the behavioral part of emotion regulation. The cognitive part of emotion regulation has been studied in relation to parenting style and child's gender insufficiently and not at all in relation to family type. Therefore, the present study investigated whether parenting style can determine that a child would employ adaptive or less adaptive strategies in 
regulating emotions and whether the type of family (nuclear/extended) and child's gender have any impacts on such regulation.

\section{Materials and Methods}

Participants: 206 children (40\% boys, 60\% girls) aged 12-15 from four randomly chosen secondary schools of Dhaka City participated in the study. Of the participants, 48 were from grade VII, 44 from grade VIII, 44 from grade IX and 70 from grade X. The grades were chosen at random, one from each selected school. $71 \%$ of the participants came from nuclear families and $29 \%$ from extended families.

Measures: Two psychometric measures were used in the study. These were the Cognitive Emotion Regulation Questionnaire (CERQ) and the Parental Authority Questionnaire (PAQ). The CERQ is a 36-item questionnaire originally developed by Garnefski et al. (2002). It is a five-point Likert type scale ranging from 1 (almost never) to 5 (almost always). The scale has nine sub-scales, each consisting of four items, each item referring to what someone thinks after the experience of threatening or stressful life events. The sub-scales are grouped broadly into Adaptive and Less Adaptive emotion regulation strategies. The adaptive strategies are acceptance, positive refocusing, refocus on planning, positive reappraisal, and putting into perspective. The less adaptive strategies include self-blame, rumination, catastrophizing and blaming others. The subscales have good internal consistencies ranging from 0.68 to 0.83 and test-retest reliabilities ranging from 0.48 to 0.65 and the CERQ has good factorial validity, discriminant validity and construct validity (Garnefski et al. 2002). In this study, the scale was translated into Bangla and adapted within the socio-cultural context of Bangladesh by administering on a sample of 100 secondary school students. The splithalf reliability of the Bangla version as calculated by the Spearman-Brown formula is 0.78 . As reported by the judges the Bangla version has good content and face validity.

The PAQ is a 30-item measure originally developed by Buri (1991). It is a five-point Likert type scale ranging from 1 (disagree) to 5 (agree). The scale has three subscales, namely authoritative parenting, authoritarian parenting and permissive parenting. Each sub-scale contains 10 items. Cronbach $\alpha$ coefficients for the sub-scales are $0.61,0.79$ and 0.72 respectively. The full scale has Cronbach $\alpha$ coefficients of 0.74 to 0.87 and testretest reliabilities of 0.77 to 0.92 (Buri 1991). The construct validity of the original scale was tested by correlating parenting style with self-esteem. As in the above, the scale was translated into Bangla and adapted within the socio-cultural context of Bangladesh. The Bangla version has good content and face validity as reported by the judges. The splithalf reliability of the full scale calculated by the Spearman-Brown formula is 0.72 .

Procedures: Standard data collection procedures were followed in the study. One of the authors of this paper personally met each head of the selected schools, briefed about the general purpose of the study and got permission to collect relevant data from the 
students. At the beginning of survey administration, good rapport was established with the students. The surveys were distributed to them individually asking to read the instructions printed on questionnaires, record the socio-demographic information (e.g., age, gender, class, family type, socio-economic status) and respond to the items. Necessary clarifications were made whenever they faced any problems to understand the items. Thus the CERQ and the PAQ were administered to them at a single sitting. They responded to the CERQ followed by the PAQ. Thus data collection was completed in four selected schools.

Data Analysis: Participants' responses were scored according to the scoring systems of the PAQ and CERQ respectively. Each participant received three types of scores on the PAQ: permissive score, authoritative score and authoritarian score, and two scores on the CERQ: adaptive score and less adaptive score. As the present study was correlational in its design, data were analyzed in multiple regressions using 'Enter' method on SPSS with overall adaptive and overall less adaptive emotion regulations as criterion/dependent variables and permissive, authoritative, authoritarian parenting, family type (levels: nuclear and extended) and child's gender (levels: male and female) as predictor/independent variables. Major assumptions of the multiple regression analysis (linearity, normality, homoscedasticity and multi-collinearity) were met in the present data.

\section{Results and Discussion}

The results of this study are illustrated below showing how children's adaptive cognitive emotion regulation and less adaptive cognitive emotion regulation vary with parenting style, but not with family type and child's gender.

Adaptive Cognitive Emotion Regulation: A significant regression model was emerged explaining $17.3 \%$ of the variance in adaptive cognitive emotion regulation (Adjusted $R^{2}=0.173 ; F=9.579, p<.001$ ). Table1 indicates that adaptive cognitive emotion regulation has a functional relationship with parenting style. As revealed by the standardized $\beta$, authoritative parenting style $(\beta=.376, p<.001)$ was the strongest predictor of adaptive cognitive emotion regulation when the variance explained by all other variables in the model was controlled. A second significant predictor of this type of emotion regulation was the authoritarian parenting style $(\beta=.197, p<.005)$. Thus a change of 1 standard deviation in authoritative parenting resulted in a change of .376 standard deviations in adaptive cognitive emotion regulation, whereas a change of 1 standard deviation in authoritarian parenting resulted in a change of .197 standard deviations in adaptive cognitive emotion regulation. Part correlation coefficients for the authoritative and authoritarian parenting styles were .334 and .190 respectively (not shown in table). When computed their unique contributions (squared of part correlation multiplied by 100), authoritative parenting style excelled (11.16\%) over authoritarian parenting style (3.61\%). Furthermore, when 
Table 1. Regression of adaptive cognitive emotion regulation on permissive parenting, authoritative parenting, authoritarian parenting, family type and child's gender.

\begin{tabular}{|c|c|c|c|c|c|}
\hline \multirow[t]{2}{*}{ Predictor variables } & \multicolumn{2}{|c|}{$\begin{array}{l}\text { Unstandardized } \\
\text { coefficients }\end{array}$} & \multirow{2}{*}{$\begin{array}{c}\begin{array}{c}\text { Standardized } \\
\text { coefficients }\end{array} \\
\beta\end{array}$} & \multirow[b]{2}{*}{$t$} & \multirow[b]{2}{*}{$p$} \\
\hline & $B$ & $S E$ & & & \\
\hline (Constant) & 36.68 & 6475 & & 5.66 & 0001 \\
\hline Permissive parenting & $\begin{array}{l}50.00 \\
.121\end{array}$ & $\begin{array}{l}0.4 / J \\
.187\end{array}$ & .047 & .646 & .519 \\
\hline Authoritative parenting & .641 & .122 & .376 & 5.256 & .0001 \\
\hline Authoritarian parenting & .317 & .106 & .197 & 2.995 & .003 \\
\hline $\begin{array}{l}{ }^{1} \text { Family type (nuclear) } \\
{ }^{2}\end{array}$ & 2.451 & 1.793 & .088 & 1.367 & .173 \\
\hline ‘Child’s gender (male) & -2.29 & 1.725 & -.087 & -1.32 & .187 \\
\hline
\end{tabular}

Adjusted $R^{2}=0.173(F=9.579, p<.001)$

Note: ${ }^{1}$ Family type $(\mathrm{N})$ was used here and subsequently as a dummy variable coded as ' 1 ' or ' 0 '. ' 1 ' stands for membership of a nuclear family and ' 0 ' stands for non-membership of a nuclear family. So, when ' 1 ' changes to ' 0 ' the variable switches to Family Type (Extended). The same logic applies for ${ }^{2}$ Child's gender $(\mathrm{M})$ variable.

data for each adaptive strategy were analyzed separately, results were highly consistent with the results for overall adaptive cognitive emotion regulation as above. That is, authoritative parenting was the strongest and/or only predictor of the child's scores in positive refocusing $(\beta=.341, p<.001)$, refocus on planning $(\beta=.286, p<.001)$, positive reappraisal $(\beta=.310, p<.001)$ and putting into perspective $(\beta=.256, p=.001)$ strategies. Although authoritarian parenting was identified as a significant predictor of positive refocusing $(\beta=.138, p<.05)$ and putting into perspective $(\beta=.183, p=.01)$ strategies it was weaker than authoritative parenting. However, none of the variables explained child's score in acceptance strategy.

The above findings suggest that authoritative parenting works best for adaptive emotion regulation (i.e., rational and positive thoughts, happy and pleasant thoughts) in children. The present findings are consistent with the past findings. For example, past studies found that children reared by authoritative parents show higher levels of social competence (Baumrind 1978), a greater ability to regulate emotions, high social skills (Isley et al. 1996) and self-regulation (Baumrind 1967). They also excel in areas of independence, creativity, persistence, academic competence, leadership skills, and social perspective taking (Baumrind 1967, 1991, 1993). Why is authoritative parenting conducive for adaptive cognitive emotion regulation in children? As discussed earlier in this paper, authoritative parents set reasonable demands on and have high expectations for their children while being warm and responsive. As parents give them chance to explore the event, they can analyze and handle the situation more efficiently, and approach forward to reach the goals. They can develop thoughts to give a positive meaning even to the negative and stressful events. Baumrind (1978) explained that 
authoritative parents openly discuss the problems or actions that may arise in relation to the child and exhibit firm control when necessary.

Less Adaptive Cognitive Emotion Regulation: The regeression model was also significant here which explained $7.1 \%$ of the variance in less adaptive cognition emotion regulation (Adjusted $R^{2}=.071, F=4.135, p=.001$ ). Table 2 indicates that the less adaptive cognitive emotion regulation has a functional relationship with parenting style. As revealed by the standardized $\beta$, authoritarian parenting style $(\beta=.294, p<.001)$ was the strongest and only significant predictor of less adaptive cognitive emotion regulation when the variance explained by all other variables in the model was controlled. Thus a change of 1 standard deviation in authoritarian parenting resulted in a change of .294 standard deviations in less adaptive cognitive emotion regulation. Part correlation coefficient for this predictor was .283 (not shown in table) indicating that authoritarian parenting alone contributes $8.01 \%$ (squared of part correlation multiplied by 100 ) of the

Table 2. Regression of less adaptive cognitive emotion regulation on permissive parenting, authoritative parenting, authoritarian parenting, family type and child's gender.

\begin{tabular}{lccccc}
\hline \multirow{2}{*}{ Predictor variables } & \multicolumn{2}{c}{$\begin{array}{c}\text { Unstandardized } \\
\text { coefficients }\end{array}$} & \multicolumn{3}{c}{ Standardized coefficients } \\
\cline { 2 - 6 } & $B$ & $S E$ & $\beta$ & $t$ & $p$ \\
\hline (Constant) & 34.597 & 5.394 & & 6.414 & .0001 \\
Permissive parenting & .166 & .156 & .083 & 1.064 & .289 \\
Authoritative parenting & -.028 & .102 & -.021 & -.273 & .785 \\
Authoritarian parenting & .371 & .088 & .294 & 4.210 & .0001 \\
${ }^{1}$ Family type (nuclear) & -.053 & 1.493 & -.002 & -.035 & .972 \\
${ }^{2}$ Child's gender (male) & -.950 & 1.437 & -.046 & -.661 & .509 \\
\hline
\end{tabular}

Adjusted $R^{2}=.071(F=4.135, p<.001)$

variance in less adaptive cognitive emotion regulation. Furthermore, when data for each less adaptive strategy were analyzed separately, results were consistent with the results for the overall less adaptive cognitive emotion regulation as above. That is, authoritarian parenting was the strongest and only predictor of child's scores in self-blame $(\beta=.235$, $p<.001)$, rumination or focus on thought $(\beta=.262, p<.001)$ and catastrophizing $(\beta=.214$, $p<.005)$ strategies. However, none of the variables explained child's score on blaming others.

The above findings suggest that authoritarian parenting leads to a less adaptive emotion regulation in children. The positive association of authoritarian parenting with less adaptive cognitive emotion regulation indicates that children of authoritarian parents always emphasize their thoughts of negative aspects of the situation. Consistent with these findings past studies have shown that authoritarian parenting is positively associated with the child's negative outcomes and negatively with the positive outcomes such as self-esteem (Buri et al. 1987). Authoritarian parents are obedience- and status- 
oriented, and expect their orders to be obeyed without explanation (Baumrind 1991). They are demanding and unresponsive to the emotional needs of the child, as well as being controlling, detached and unsupportive (Baumrind 1967). Thus offering one-way style of parenting authoritarian parents might block the development of emotion regulation in adaptive manner, increasing the likelihood that the child will be less adaptive in interaction with the surroundings.

The study further revealed that permissive/indulgent parenting has a neutral role in developing cognitive emotion regulation making children neither adaptive nor less adaptive (Tables 1 and 2). As permissive parents exhibit high levels of warmth and low levels of control, children of these parents become neither adaptive nor less adaptive in emotional setting. Research has shown that children of permissive parents get inconsistent and confusing guidelines or no outlines of the boundaries in their environment (Baumrind 1967). Under such parenting, little is required of children, especially in the areas of maturity and responsibility (Baumrind 1991). Also, permissive parents often surrender to the demands of their child. According to Baumrind (1968), children of permissive parents are often left to regulate their own activities, behavior, and emotions at a young age.

One important aspect of the findings is that children's cognitive emotion regulation is not associated with the type of family they are raised in (Tables 1 and 2). Family is the first and foremost important psychosocial setting for every child. According to Karim et al. (2004), to know the future of a society one should look into the ways the children are raised in, but not into the family structure. As the difference in family structure did not produce any difference in children's cognitive emotion regulation in this study, we give more importance on quality parenting over family structure, suggesting that all parents should be trained on good parenting rather than family structure. However, there are studies demonstrating that family type can facilitate or limit the ways in which parents are able to positively influence the outcomes of their children (Amato 2001, Amato and Keith 1991, Sigle-Rushton and McLanahan 2002). But, in those studies the concept of family type was different from what we mean by family type in the present study. As demonstrated by Amato (2001), for example, children coming from divorced families have more difficulties in school, more behavior problems, more negative self-concept and more trouble getting along with their parents. Children who live with a single mother family fare poorly across a wide range of adolescent and adult outcomes, including educational attainment, economic security and physical and psychological well-being (Sigle-Rushton and McLanahan 2002). Thus whether family type is important for the child's emotional or other psychosocial development depends on how it is defined. A family type just defined by the number of people living together is not important at all.

Another interesting demonstration is the gender equality in children's cognitive emotion regulation. This is inconsistent with the findings in other cultures (Zlomke and Hahn 2010, Martin and Dahlen 2005, Garfenski 2004). American women scored higher on 
rumination, catastrophizing, positive refocusing, refocusing on planning and positive reappraisal whereas American men scored higher on blaming others (Martin and Dahlen 2005). Likewise, Dutch women reported to use rumination, catastrophizing and positive refocusing more often than Dutch men (Garfenski 2004). Nowadays, parents in Bangladesh are conscious enough to deal with the male and female children alike, thus promoting no difference in cognitive emotion regulation between the two sexes.

In summary, the study demonstrated that the style of parenting determines the cognitive strategies children will employ to regulate their emotions. Of the three types of parenting, authoritative parenting was the best for children's adaptive cognitive emotion regulation, and authoritarian for less adaptive cognitive emotion regulation. Permissive parenting has no impact on children's cognitive emotion regulation. Type of family or child's gender has also nothing to do with such functioning. It can, therefore, be concluded that good parenting style as characterized by parental warmth, acceptance, and readiness for childhood needs and proper control is crucial for adaptive emotion regulation at adolescent period and to handle the problems skillfully.

Limitations and Implications: The present study offers some inconsistent results. For example, authoritarian parenting contributes significantly in both the adaptive and less adaptive cognitive emotion regulations. This was unexpected and cannot be explained by the present data. The study has also some inherent limitations such as it cannot explain a large proportion of the variance in cognitive emotion regulation. Further research on a large scale sample from different parts of Bangladesh will possibly exclude the inconsistency.

Despite the above limitations, the present findings will have important implications for research and practice. The findings will give rise to new researches in family matters, parental practices and adolescents' outcomes. For practice, the study provides important information about the good parenting need in adolescence. Adolescence is a very sensitive age, when guidance and proper press of their emotion and emotion regulation must go together with affection, support, and freedom. The findings will be helpful for parents, caregivers, child psychologists, and other professionals working with children or adolescents for guiding them to become resources of the country.

\section{Acknowledgements}

Authors are thankful to N. Garnefski, Department of Psychology, Division of Clinical and Health Psychology, University of Leiden, PO Box 9555, 2300 Leiden, The Netherlands, who permitted to translate and use the CERQ, and to J. Buri, Department of Psychology, University of St. Thomas, St. Paul, MN 55105, USA, who permitted to translate and use the PAQ in this research. 


\section{References}

Amato, P. 2001. Children of divorce in the 1990s: An update of the Amato and Keith (1991) metaanalysis. Journal of Family Psychology. 15 (3): 355-370.

Amato, P. and B. Keith. 1991. Parental divorce and the well-being of children: A meta-analysis. Journal of Marriage and the Family. 53(1): 43-58.

Baumrind, D. 1967. Child care practice anteceding three patterns of preschool behavior. Genetic Psychology Monographs, 75(1): 43-88.

Baumrind, D. 1968. Authoritarian vs. authoritative control. Adolescence. 3(11): 255-272.

Baumrind, D. 1978. Reciprocal rights and responsibilities in parent-child relations. Journal of Social Issues. 34(2): 179-196.

Baumrind, D. 1991. The influence of parenting style on adolescent competence and substance use. Journal of Early Adolescence.11(1): 56-95.

Baumrind, D. 1993. The average expectable environment is not good enough: A response to Scarr. Child Development. 64(5): 1299-1317.

Baumrind, D. and A.E. Black. 1967. Socialization practices associated with dimensions of competence in preschool boys and girls. Child Development. 38(2): 291-327.

Berndt, T.J. 1979. Developmental changes in conformity to peers and parents. Developmental Psychology. 15(6): 608-616.

Buri, J.R. 1991. Parental authority questionnaire. Journal of Personality and Social Assessment. 57(1): 110-119.

Buri, J.R., P.A. Kirchner and J.M. Walsh. 1987. Familial correlates of self-esteem in young American adults. Journal of Social Psychology. 127(6): 583-588.

Garnefski, N., J. Teerds, V. Kraaij, J. Legerstee and T. van den Kommer. 2004. Cognitive emotion regulation strategies and depressive symptoms: Differences between males and females," Personality and Individual Differences. 36(2): 267-276.

Garnefski, N., T.van den Kommer, V. Kraaij, J. Teerds, J. Legerstee and E. Onstein. 2002. The relationship between cognitive emotion regulation strategies and emotional problems: comparison between a clinical and a non-clinical sample. European Journal of Personality. 16(5): 403-420.

Hart, C.H., D.A. Nelson, C.C. Robinson, S.F. Olsen and M.K. McNeilly-Choque. 1998. Overt and relational aggression in Russian nursery-school-age children: Parenting style and marital linkages. Developmental Psychology. 34(4): 687-697.

Hart, C.H., L.D. Newell and S.F. Olsen. 2003. Parenting skills and social-communicative competence in childhood, In: J.O. Greene and B.R. Burleson (Eds.), Handbook of communication and social interaction skills. NJ: Lawrence Erlbaum, Mahwah. pp.753797.

Isley, S., R. O’Neil and R.D. Parke. 1996. The relation of parental affect and control behaviors to children's classroom acceptance: A concurrent and predictive analysis. Early Education and Development. 7(1): 7-23.

Karim, A.K.M.R., S. Islam and M.S. Seraj. 2004. Self-concept and family structure: A comparison between the children of joint and nuclear families. The Dhaka University Studies. 61(2): 171-182.

Martin, R.C. and E.R. Dahlen. 2005. Cognitive emotion regulation in the prediction of depression, anxiety, stress, and anger. Personality and Individual Differences. 39(7): 1249-1260.

McLanahan, S.S. and L. Bumpass. 1988. Integenerational consequences of family disruption. American Journal of Sociology. 94(1): 130-152.

Mize, J. and G.S. Pettit. 1997. Mothers social coaching, mother-child relationship style, and children's peer competence: Is the medium the message? Child Development, 68(2): 312332.

Nix, R.L., E.E. Pinderhughes, K.A. Dodge, J.E. Bates, G.S. Pettit and S.A. McFadyen-Ketchum. 1999. The relation between mothers' hostile attribution tendencies and children's 
externalizing behavior problems: The mediating role of mothers' harsh discipline practices. Child Development. 70(4): 896-909.

Sigle-Rushton, W. and S. McLanahan, 2002. Father absence and child well-being: A critical review. Working paper, Princeton, NJ: Center for Research on Child Wellbeing. pp. 0220.

Thompson, R.A. 1994. Emotional regulation: A theme in search for definition. Monographs of the Societyfor Research in Child Development. 59(2/3): 25-52.

Young, H. and B.F. Fergusan. 1979. Developmental changes through adolescence in spontaneous nomination of reference groups as a function of decision content. Journal of Youth and Adolescence. 8(2): 239-252.

Zlomke, K.R. and K.S. Hahn. 2010. Cognitive emotion regulation strategies: Gender differences and associations to worry. Personality and Individual Differences. 48(4): 408-413.

(Received revised manuscript on 25 September 2013) 